\title{
GERAÇÃO ESPONTANEA E EVOLUÇÃO QUÍMICA GRADUAL EM LIVROS DIDÁTICOS DO ENSINO FUNDAMENTAL
}

\author{
SPONTANEOUS GENERATION AND GRADUAL CHEMICAL EVOLUTION IN \\ SCHOOL TEXTBOOK
}

\author{
Ana Laura Pureza Pantoja ${ }^{1}$ \\ ORCID iD: $\underline{0000-0003-3238-6000}$
}

Eduardo Paiva de Pontes Vieira ${ }^{2}$

ORCID iD: 0000-0003-1641-7014

\section{RESUMO}

\begin{abstract}
Origem da Vida, enquanto conteúdo curricular, constitui uma temática de natureza controversa. Conhecimentos de várias áreas sustentam diversas hipóteses e cenários plausíveis para explicar como a vida se originou na Terra, abrindo espaço para os conflitos que existem nesse âmbito, além de expressar características da natureza do conhecimento científico. É nessa perspectiva que essa abordagem pode ser vinculada com a História e Filosofia da Ciência (HFC), para que não sejam reforçadas visões de Ciência que remetam à linearidade da construção do conhecimento e à ausência de conflitos. A Análise do Discurso, proposta nos trabalhos de Michel Foucault, pode ser utilizada como dispositivo analítico para pensar a abordagem de História e Filosofia da Ciência preconizada em livros didáticos. Sendo assim, este trabalho tem como objetivo circunscrever qual(is) discurso(s) circula $(\mathrm{m})$ sobre as teorias movimentadas no conteúdo escolar "Origem da Vida", estritamente em relação às teorias da geração espontânea e da evolução química gradual, em livros didáticos de Ciências do $7^{\circ}$ ano do Ensino Fundamental. A análise indica que as Teorias da Evolução Química Gradual e da Geração Espontânea são recorrentes nos livros didáticos, com uma vertente historiográfica positivista, compondo enunciados que estabelecem as possibilidades de circulação e de legitimação do conhecimento científico.
\end{abstract}

Palavras-chave: Origem da Vida. Livro Didático. Ensino de Ciências. História e Filosofia da Ciências.

\begin{abstract}
Origin of Life, as curricular content, is a controversial topic. Knowledge from various areas supports several hypotheses and plausible scenarios to explain how life originated on Earth, making room for the conflicts that exist in this matter, in addition to expressing characteristics of the nature of scientific knowledge. It is in this perspective that the approach can be linked with the History and Philosophy of Science (HPS), so that views of science that refer to the linearity of knowledge construction and the absence of conflicts are not reinforced. The discourse analysis proposed by Michel Foucault can be used as an analytical device to think about the approach of History and Philosophy of Science recommended in textbooks of basic education. Therefore, this work aims to see which discourse(s) go about the theories on the school content "Origin of Life", strictly in relation to the theories of Spontaneous Generation and Gradual Chemical Evolution, in the

\footnotetext{
${ }^{1}$ Mestra em Educação Científica e Matemática pela Universidade Federal do Pará (UFPA). Belém, Pará, Brasil. Endereço para correspondência: Rua Augusto Corrêa, 01, Guamá, Belém, Pará Brasil, CEP: 66075-110. E-mail: analaurapantoja1411@hotmail.com. Educação em Ciências e Matemática - PPGDOC/UFPA. Belém, Pará, Brasil. Endereço para correspondência: Rua Augusto Corrêa, 01, Guamá, Belém, Pará Brasil, CEP: 66075-110. E-mail epontesvieira@ @mail.com / eppv@ ufpa.br.
}

${ }^{2}$ Doutor em Educação Científica e Matemática pela Universidade Federal do Pará (UFPA). Professor dos Programas de Pós-Graduação em Educação em Ciências e Matemáticas - PPGECM/UFPA e Pós-Graduação em Docência em
\end{abstract}


elementary school textbooks for the 7th grade. The analysis indicates that the Theories of Gradual Chemical Evolution and Spontaneous Generation are recurrent in textbooks with a positivist historiographical aspect, composing statements that establish the potential circulation and legitimation of scientific knowledge.

Keywords: Origin of Life. Textbooks. Science Teaching. History and Philosophy of Science.

\section{INTRODUÇÃO}

O Ensino de Ciências defendido atualmente tem como objetivo construir uma base de conhecimentos contextualizados para preparar o discente ao exercício pleno de sua cidadania, a fim de que ele possa investigar, analisar e discutir problemas que emergem dos diferentes contextos socioculturais, assim como compreender e interpretar as leis, os modelos e as teorias cientificas, aplicando-os na resolução desses problemas (BRASIL, 2018). Nesse viés, propõe-se que as práticas tradicionais de memorização e repetição sejam superadas. Hidalgo e Junior (2016) consideram a inserção da História e Filosofia da Ciência (HFC) uma ferramenta de apoio na promoção crítica nos ambientes de aprendizagem. Nesta perspectiva, o professor ficaria incumbido, então, de possibilitar o diálogo entre o assunto científico trabalhado em sala de aula, a história desses saberes e os seus pressupostos epistemológicos, utilizando-se de instrumentos pedagógicos que o auxiliem nesse sentido.

A Origem da Vida, segundo Ouverney e Lage (2016), é um conteúdo cujos desdobramentos permanecem relacionados com conflitos no meio científico e religioso, ganhando relevância nos contextos educacionais e na formação científica, humana e social dos discentes. Esse pensamento fica em evidência na repercussão dos episódios de conflito entre a teoria da geração espontânea e a teoria da evolução química gradual, presentes nas práticas educacionais dessa temática, que podem ser visualizados em materiais didáticos, tais como o livro didático que, segundo Souza (2014), pode ser visto como uma ferramenta essencial ao trabalho pedagógico, por ser a base, muitas vezes, da sistematização e da organização das aulas dos professores.

Questões relacionadas com as abordagens contemporâneas em História e Filosofia da Ciência, vinculadas à temática da Origem da Vida, nos livros didáticos, emergem e justificam movimentos de pesquisas que conduzem para a construção de respostas sobre os aspectos dessas abordagens. Assim, preconiza-se uma nova vertente, com foco na historicidade do discurso científico de determinado tempo e cultura. A História das Ciências possui quatro vertentes epistemológicas, mais ou menos evidentes, que orientam teoricamente e metodologicamente a produção desses saberes até os dias de hoje. A primeira vertente, de grande influência iluminista, considerada como uma "pré-história da Ciência", e a segunda vertente, influenciada pelo 
positivismo de Augusto Comte, na qual a Ciência constitui um saber universal, objetivo, focado nos grandes cientistas. A terceira vertente, influenciada pela dialética marxista, demarca o desenvolvimento científico, a partir da técnica e da economia. A quarta vertente, conhecida como História da Ciência Contemporânea, parte do princípio de que a Ciência é um saber determinado pela natureza e pelo meio cultural no qual se insere, fugindo da visão de um saber universal e superior, enfatizando o saber produzido no âmbito sociocultural (MACHADO, 2016).

Analisar enunciados com a intenção de delimitar discursos pode orientar novas discussões e possibilitar olhares diferenciados. Assim, consideramos, da mesma forma que Alvim e Zanotello (2014), que a Análise do Discurso, especificamente, em referência aos trabalhos de Michel Foucault, pode ser utilizada como dispositivo analítico para pensar nessa produção e abordagem da HFC. Segundo Foucault (2004), não se tem o direito de falar qualquer coisa a qualquer um. Por isso, há determinadas coisas que, de acordo com a circunstância e o contexto, podem ou não ter condição de fala. Isso porque o que é dito está impregnado, para o autor, pelo discurso que tem sua vontade de verdade, suas relações de poder-saber, sua produção e sua circulação historicamente localizada, entre outras características e elementos.

Levando esse pensamento para os estudos na área da educação, torna-se evidente a conexão existente entre escola, linguagem e, consequentemente, o discurso. Barnes (1976) concebe a sala de aula como um espaço essencialmente embasado na comunicação. Logo, a fala do professor, impregnada pelo discurso, é capaz de produzir o pensamento, o comportamento e a visão de mundo do aluno. Esse espaço de produtividade é constituído por dispositivos ${ }^{3}$, dentre os quais, o material didático que nele circula, destacando-se os livros didáticos, conforme o argumento:

Os livros didáticos representam a principal, senão a única fonte de trabalho como material impresso na sala de aula, em muitas escolas da rede pública de ensino, tornando-se um recurso básico para o estudante e para o professor, no processo ensino-aprendizagem (FRISON et al., 2009, p. 4).

O Plano Nacional do Livro Didático (PNLD) é responsável pela avaliação e pela distribuição dos livros didáticos, desde a instituição do Decreto $\mathrm{n}^{\circ}$ 91.542, de 19 de agosto de 1985 , contando com a participação de professores do Ensino Fundamental, no processo de escolha desses materiais. Segundo Cassiano (2007), em 1996, ocorreu a implantação da avaliação dos livros didáticos, resultando no Guia de Livro Didático, material disponibilizado publicamente para auxiliar professores da educação básica, com resenhas dos livros aprovados.

\footnotetext{
${ }^{3}$ Dispositivo, na perspectiva de Foucault, entendido como uma rede estabelecida entre o poder e as formações sociais, na relação entre discurso e a prática, ideias e ações, atitudes e comportamentos - algo que se aplica às formações sociais, nas quais estão implicadas diversas dimensões que devem ser consideradas para a sua compreensão e que também são constitutivas do discurso (KLEIN, 2007).
} 
Segundo o Guia do Livro Didático: Ciências 2017, alguns critérios específicos deveriam ser contemplados nos componentes curriculares das coleções, possuindo caráter eliminatório, caso não houvesse a presença de algum elemento exigido. Dentre os critérios específicos para as Ciências Naturais, encontramos a abordagem relacionada com a História e Filosofia da Ciência, evidenciando a necessidade de uma história da Ciência muito além de nomes ou datas, que explorasse o contexto social, cultural, econômico e político em que ocorreu a produção científica (BRASIL, 2016, p.28).

Esse critério específico suscita questionar se a abordagem HFC está efetivamente sendo empregada e/ou sobre qual(is) vertente(s) historiográfica(s) podem ser visualizadas no material didático. Com efeito, as práticas discursivas empreendidas em determinadas abordagens produzem práticas de ensino que podem ser discutidas e problematizadas em relação aos diferentes conteúdos científicos. Sendo assim, este trabalho tem como objetivo circunscrever qual(is) discurso(s) circula(m) sobre as teorias movimentadas no conteúdo escolar "Origem da Vida", estritamente em relação às teorias da geração espontânea e da evolução química gradual, em livros didáticos de Ciências do $7^{\circ}$ ano do Ensino Fundamental.

\section{PRESSUPOSTOS METODOLÓGICOS}

Trata-se de uma pesquisa qualitativa que, segundo Minayo (2013, p.79), tem como foco "a exploração do conjunto de opiniões e representações sociais sobre o tema que se pretende investigar", evidenciando o que é homogêneo e o que se diferencia nas informações geradas dentro do mesmo meio ou elemento social, norteada pela Análise do Discurso referenciada nos escritos de Michel Foucault, utilizando-se dos seus pressupostos de enunciado e discurso.

O ponto inicial desta análise refere-se ao conteúdo curricular presente em livros didáticos do $7^{\circ}$ ano do Ensino Fundamental, a partir de uma observação empírica das informações e das apresentações contidas nos livros didáticos, utilizados no ensino de Ciências, em escolas brasileiras, disponibilizados por meio do PNLD de 2017. Assim, os procedimentos de análise empreendidos nesta pesquisa objetivam fundamentalmente evidenciar enunciados e circunscrever discursos relacionados ao tema, possibilitando a construção de inferências com possibilidades para a formação crítica e novas análises que considerem a História e Filosofia da Ciência nos processos de ensino e de formação.

Dentre as 13 coleções aprovadas no PNLD 2017, 4 livros (Quadro 1) adentraram no grupo de livros didáticos analisados. A escolha dos livros didáticos deu-se pela acessibilidade ao material, por fazerem parte do PNLD 2017, e por serem livros que possuem textos ou capítulos referentes às 
teorias da geração espontânea e da evolução química gradual, pertencentes à temática da Origem da Vida.

\begin{tabular}{|c|c|c|}
\hline Título da Edição & Autor(es) & Editora \\
\hline $\begin{array}{c}\text { Projeto Teláris - } \\
\text { Ciências }\end{array}$ & Fernando Gewandsznajder & Editora Ática \\
\hline $\begin{array}{c}\text { Projeto Araribá - } \\
\text { Ciências }\end{array}$ & Maríra Rosa Carvenalle & Moderna \\
\hline $\begin{array}{c}\text { Companhia das } \\
\text { Ciências }\end{array}$ & $\begin{array}{c}\text { João Usberco; José Manoel } \\
\text { Carlos Ferrer \& Herick Martins } \\
\text { Velloso }\end{array}$ & Saraiva Educação \\
\hline Ciências & $\begin{array}{c}\text { José Trivellato Júnior; Silvia } \\
\text { Luiza Frateschi Trivellato; Marcelo } \\
\text { Tadeu Motokane; Júlio Cezar } \\
\text { Foschini Lisboa \& Carlos Aparecido } \\
\text { Kantor }\end{array}$ & Quinteto \\
\hline
\end{tabular}

Quadro 1 - Livros que adentraram no grupo de livros didáticos analisados Fonte: Elaborado pelos autores.

O enunciado é o que dá condição e/ou possibilidade de existência para as unidades estruturais, atravessando-as verticalmente; compondo-se, então, dos signos recorrentes dessa relação verticalizada que existe na história e no espaço, com conteúdo significativo. Assim, podemos perceber a sua existência nas diversas formas de comunicação, seja pela escrita, seja pela imagética: "um horário de trens, uma fotografia ou um mapa podem ser um enunciado, desde que funcionem como tal, ou seja, desde que sejam tomados como manifestações de um saber e que, por isso, sejam aceitos, repetidos e transmitidos" (VEIGA-NETO, 2003, p. 113).

O discurso seria, então, constituído por esse conjunto de sequência de signos, enquanto enunciados, apoiados na mesma formação discursiva, sendo também constituído de "práticas que formam sistematicamente os objetos de que falam. Certamente os discursos são feitos de signos; mas o que fazem é mais que utilizar esses signos para designar coisas" (FOUCAULT, 2008, p. 55). Isso porque, segundo Azevedo (2013, p. 156), o discurso se apresenta como um elo entre a linguagem e outras práticas do campo social, reunindo elementos tanto da sua "fabricação e ajuste dos discursos - compostos por uma unidade de enunciados - quanto da aplicação e produção destes, nas instituições e nas relações sociais, definindo assim um saber, além de determinar funções e formas de comportamento em uma época".

Foucault $(2004$, p. 8) assevera que a vontade de verdade se apoia sobre um suporte institucional, sendo reforçada e reconduzida, concomitantemente, por um conjunto de práticas, como, por exemplo, a da pedagogia com seus sistemas de livros. Mas o que reconduz, de forma mais profunda, é o "modo como o saber é aplicado em uma sociedade, como é valorizado, 
distribuído, repartido e de certo modo atribuído". Sendo assim, ele acredita que a vontade de verdade, tende a exercer, nos mais variados discursos, um poder de coerção para se consolidar.

Consequentemente, o discurso está inserido na complexa rede de relação poder-saber. Poder este que, para Foucault (2008, p. 88), não é visto como existente em um ponto central ou em um único foco de soberania, mas sim como uma "multiplicidade de correlações de forças imanentes ao domínio onde se exercem e constitutivas de sua organização". Percebe-se, então, que o discurso está distante da neutralidade e da transparência, visto que uma análise mais atenta possibilita estabelecer a rede de ligações existentes com o poder e o desejo. Assim, ele vai além de apenas manifestar o desejo ou o que traduzem os sistemas de dominações e de lutas, ele é o próprio objeto de desejo, o motivo pelo qual se luta e o poder que se quer conquistar (FOUCAULT, 2004).

Outro componente do discurso que evidenciamos nos escritos foucaultianos é o Autor ${ }^{4}$, que não é simplesmente quem escreve a obra ou o texto, mas aquele que transcende o indivíduo real e exterior, para ser um elemento discursivo que exerce uma função classificatória, a qual lhe permite agrupar textos, delimitá-los, excluir parte deles, relacionar os textos em si. Nesse sentido, temos o Autor como um instaurador de agrupamentos discursivos, permitindo o modo de existência desses discursos, como eles circulam e como determinados discursos circulam no interior de uma sociedade específica (FOUCAULT, 2009).

\section{ANÁLISES E DISCUSSÕES}

A Origem da Vida é uma temática altamente discutida e investigada no meio científico. Ainda assim, há muitas questões não respondidas. Dentre as teorias, a evolução química é a mais aceita entre os cientistas com o intuito de compreender os processos que possibilitaram o surgimento da vida (GRIMES \& SCHROEDER, 2013). Segundo Vieira (2013), pensar a vida na contemporaneidade é um movimento possibilitado por um materialismo que reuniu a profusão de reações químicas, referidas por Alexandre Oparin, em 1924. Contudo, a criação de explicações com viés químico para a Origem da Vida pode ser reificada em uma produção científica aglomerada no que podemos chamar de "Evolução Química Gradual” (ZAIA, 2003).

A evolução química gradual, baseada nos estudos da química prebiótica, em linhas gerais, sustenta que determinado conjunto de reações químicas poderia ter cooperado para o surgimento da vida na Terra, ou seja, reações químicas que, em condições de como se acredita ter sido a atmosfera

\footnotetext{
${ }^{4} \mathrm{O}$ conceito foucaultiano de Autor será utilizado nas análises para abordar os cientistas presentes nos livros didáticos, uma vez que eles não são concebidos apenas como indivíduos que propuseram hipóteses/teorias ou fizeram experimentos, mas como elementos discursivos.
} 
da Terra Primitiva, possam ter resultado em moléculas orgânicas importantes para o funcionamento e manutenção da vida como se conhecia (ZAIA, 2003). Três Autores ${ }^{5}$ destacam-se para a circulação do discurso científico da evolução química gradual: Alexander Ivanovitch Oparin (1894-1980) e J. B. S. Haldane (1892-1964) que, de forma independente, levantaram hipóteses, em 1924 e 1929 , respectivamente, que ficaram conhecidas como Hipótese de Oparin-Haldane; e Stanley Lloyd Miller (1920-2007), com seu experimento.

O bioquímico Alexander Oparin, no contexto da recém-criada União das Repúblicas Socialistas Soviética, publicou sua obra A Origem da Vida na Terra, que, posteriormente, sofreu diversas revisões e reedições, sendo "fundamental não apenas pela abordagem da tese biogenética mais difundida naquele momento, como também pelo apanhado histórico-filosófico das teorias divergentes" (BARCELOS, 1999, p.11). Influenciado pelo evolucionismo darwinista e pelo materialismo dialético de Engels, Oparin mostra em seus escritos a possibilidade de um organismo primordial, surgindo a partir da formação e da interação de compostos orgânicos já formados, conhecidos como coacervados. Algumas premissas defendidas por ele não eram populares na época, dentre essas, a ideia do primeiro organismo existente ser heterotrófico e o pressuposto de um alto grau de organização funcional do ser vivo, além da percepção de ser vivo como um sistema fechado - tais premissas resultaram na recusa inicial da hipótese (NEGRETTI, 2006).

Haldane, geneticista inglês, que era um militante marxista, aderiu à hipótese materialista de origem da vida e criou uma hipótese semelhante à de Oparin, que é conhecida atualmente como Hipótese Oparin-Haldane ou a "Teoria da Sopa Nutritiva” ou "Teoria da Sopa Prebiótica:

A Terra primitiva detinha uma composição atmosférica distinta da atual, possuindo, basicamente, vapor d'água, hidrogênio, metano e amônia. Energizados pela radiação ultravioleta - dada a inexistência da camada protetora de ozônio - e descargas elétricas (entre outras fontes possíveis de energia), tais elementos químicos agregaram-se na forma de compostos orgânicos. Formou-se, gradualmente, nos oceanos primitivos, uma "sopa" composta por moléculas constituintes dos blocos básicos da vida. Num prazo da ordem dos milhões de anos, constituíram-se os primeiros seres vivos, que passaram a reproduzir-se e, a partir daí, a iniciar um processo de seleção natural e evolução (BARCELOS, 1999, p.11).

Stanley Lloyd Miller (1930 - 2007), ao adentrar a Universidade de Chicago, começou a ver as possibilidades para o seu projeto de tese, que tinha como objetivo algo mais teórico do que experimental. Após trabalhar por quase um ano, como orientando de Edward Teller, com a temática da forma de sintetização dos elementos nas estrelas, Miller recebeu a notícia de que seu orientador se mudaria de Chicago, para cofundar um laboratório de armas atômicas no Laboratório Nacional de Lawrence Livermore, em meados de 1952. Aconselhado por muitos professores, decidiu procurar outro orientador (BADA \& LAZCANO, 2012).

\footnotetext{
${ }^{5}$ Autores (em maiúsculo), na perspectiva de Michel Foucault.
} 
Assim, Miller começou a pensar sobre um dos seminários do departamento de Química a que assistiu no ano anterior, do laureado com o Nobel de Química e Professor Harold Clayton Urey (1893 - 1981), no qual apresentou suas ideias referentes à origem do sistema solar e aos eventos químicos que se associam a esse processo, em especial, a atmosfera da Terra Primitiva ser diferente da que se conhecia na atualidade e, provavelmente, constituída por uma mistura de gases redutores com metano, amônia, sulfato de hidrogênio e hidrogênio, sugerindo que seria possível sintetizar componentes orgânicos que poderiam prover os matérias necessários para a emergência da vida (BADA \& LAZCANO, 2012).

Então, conversou com Urey sobre a possibilidade de fazer um experimento de síntese prebiótica, usando mistura de gases redutores. A ideia não agradou muito ao professor, que achava que alunos de doutorado deveriam tentar experimentos com altas chances de resultados, não um salto no escuro, mas, depois de muita insistência, aceitou orientar Miller, na condição de que, se em um ano não conseguissem nenhum resultado, a pesquisa seguiria outro caminho (BADA \& LAZCANO, 2012).

As ideias sobre a constituição gasosa, temperatura e formações oceânicas da Terra Primitiva e de que era preciso de uma entrada de alta energia para induzir as reações químicas possibilitaram a construção do aparato experimental (BADA \& LAZCANO, 2012). Em linhas gerais, o experimento ocorreu de forma que:

\begin{abstract}
A mistura dos gases metano, amônia e hidrogênio simularia a atmosfera primitiva, os eletródios gerariam faíscas que simulariam os raios e seriam fonte de energia para as reações e o frasco com água simularia o mar [...]. Após algumas semanas de reação, o frasco com água apresentava uma coloração vermelha e compostos de coloração amarela. Uma análise química da solução aquosa mostrou a existência dos aminoácidos glicina, $\alpha$-alanina, $\beta$-alanina, ácido aspártico e $\alpha$ - aminoácido-n-butílico. Já que aminoácidos são os blocos construtores das proteínas, este experimento mostrou que uma mistura simples de gases foi capaz de gerar algumas moléculas essenciais a todos os seres vivos conhecidos (ZAIA, 2003, p. 261).
\end{abstract}

A realização do experimento ocorreu com a construção de três aparelhos que tentavam simular algumas condições que se acreditava existir na Terra Primitiva. Apesar de os três aparelhos serem usados no decorrer de todo o processo experimental, apenas o aparelho 1 (Figura 1) ficou conhecido, provavelmente por ter sido mais descrito, sendo referido como Aparelho Clássico (BADA \& LAZCANO, 2012). Isso é evidenciado, quando é retratado somente o aparelho clássico, ao descrever o experimento, nos livros didáticos Companhia das Ciências (Figura 2), no Projeto Arirabá (figura 3), e no exercício do Projeto Teláris: "agora, pesquise como foi, em linhas gerais, o experimento de Miller. Depois, procure também uma ilustração do aparelho construído pelo cientista”. 


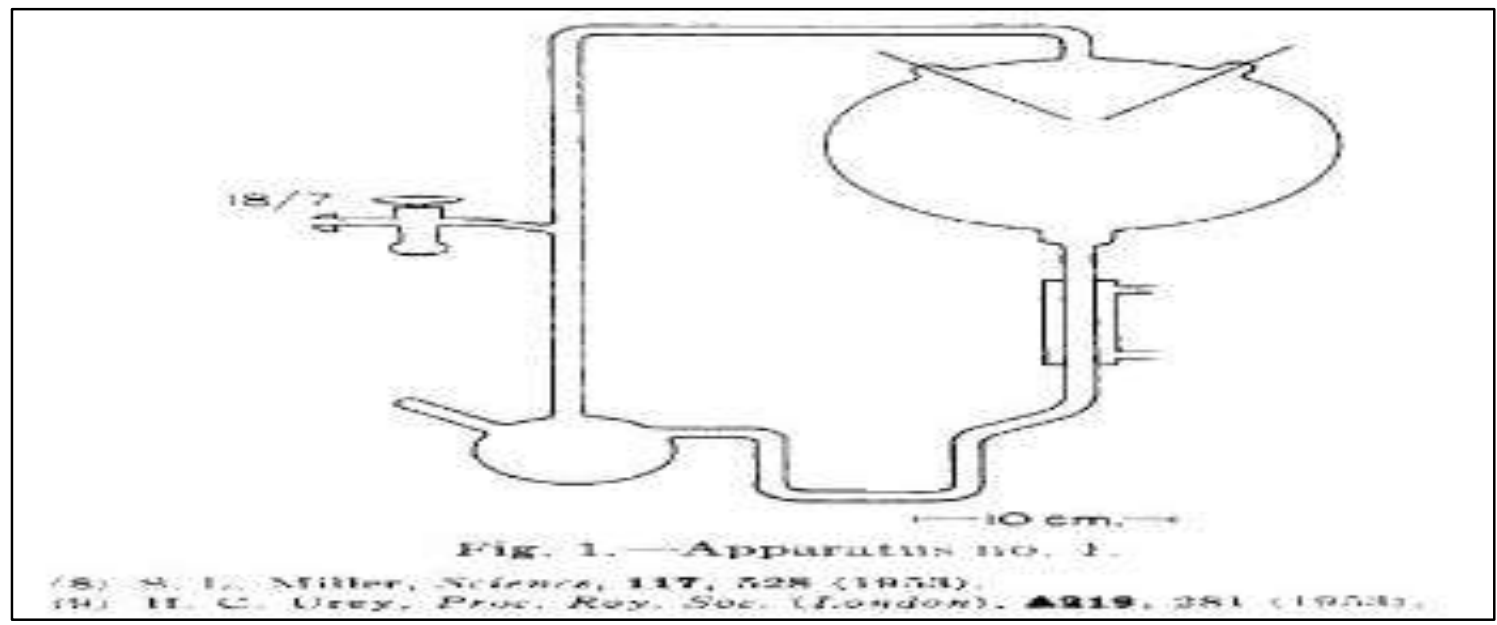

Figura 1 - Aparelho ${ }^{\circ} 1$ do experimento de Staney Miller Fonte: Miller (1955, p. 2352).

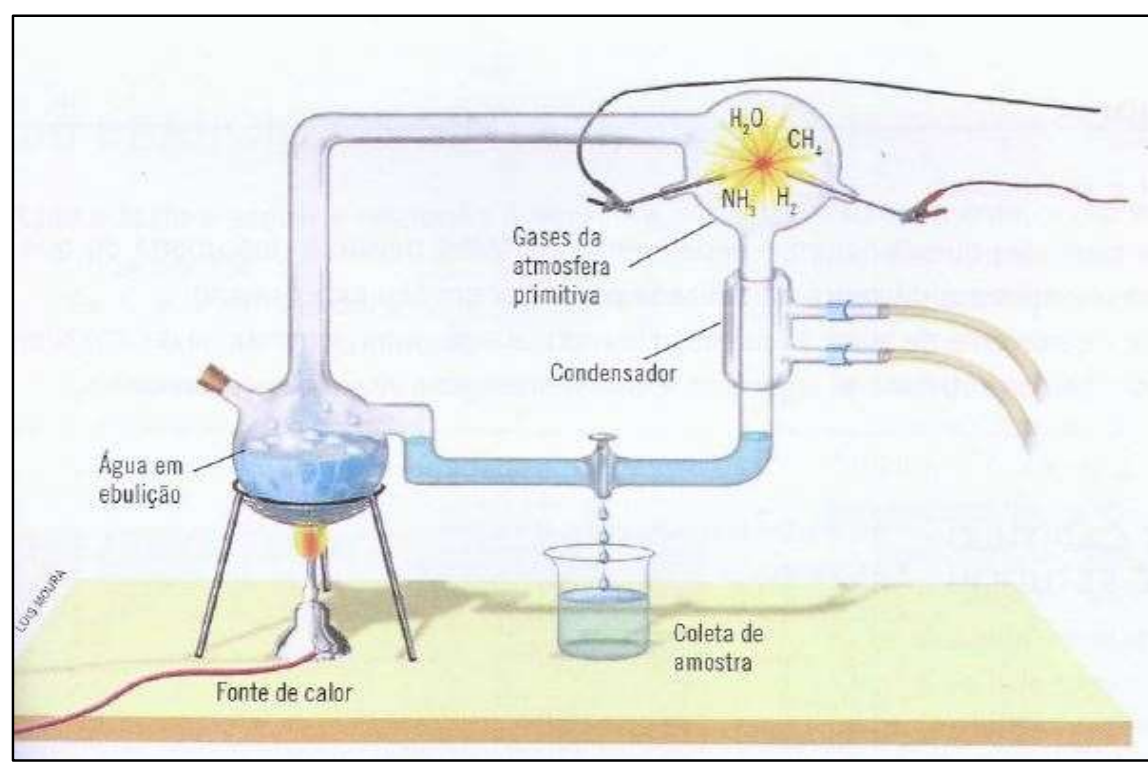

Ilustraço esquemática da aparelhagem utilizada por Miller em seu experimento (Representação fora de proporção. Cores fantasia.)

Figura 2 - Ilustração do aparelho experimental Fonte: Companhia das Ciências (2015, p. 83). 


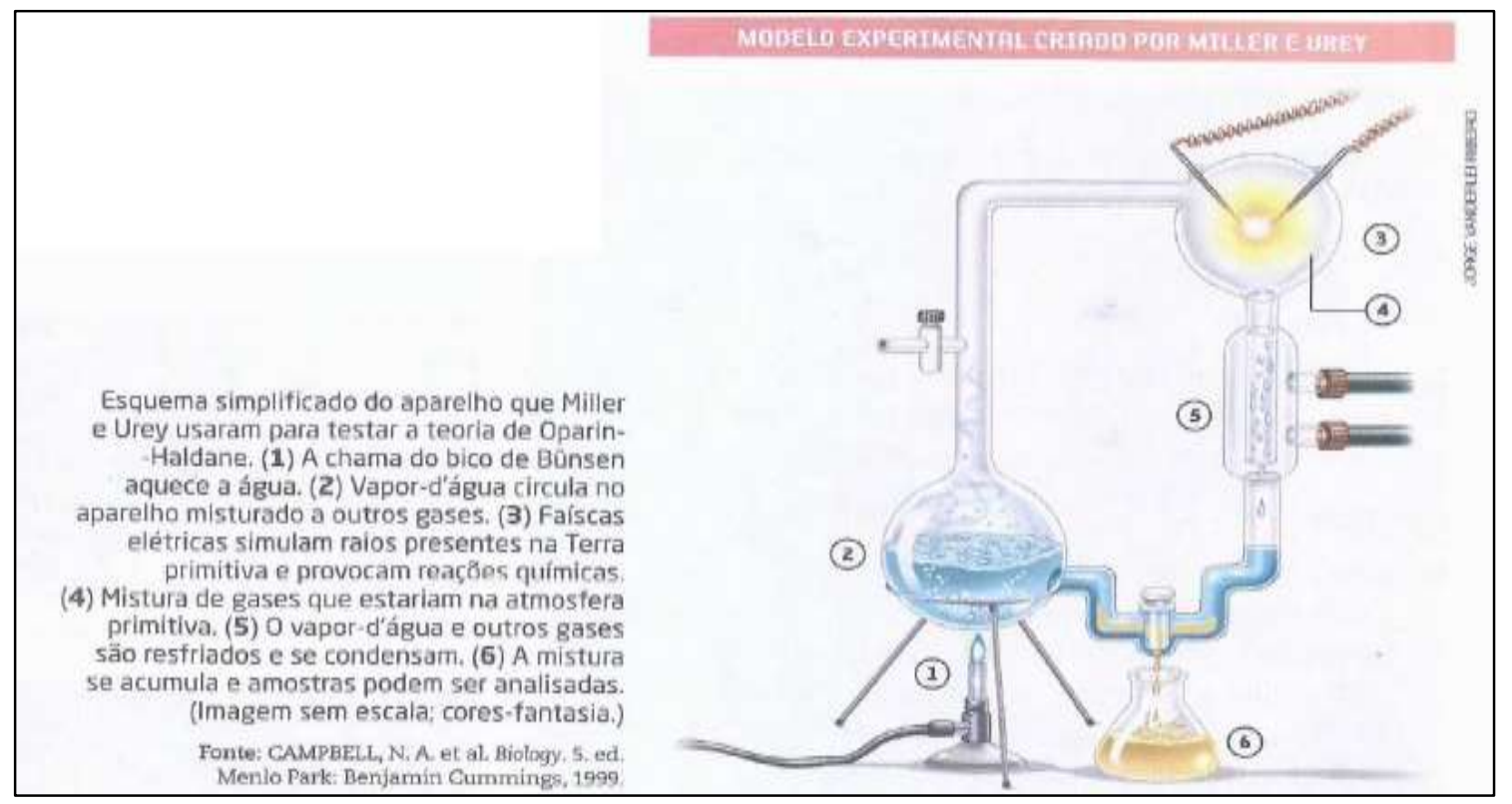

Figura 3 - Ilustração do aparelho experimental Fonte: Projeto Araribá Ciências (2014, p. 29).

Quando os resultados começaram a aparecer, Urey e Miller escreveram o artigo para submeter a uma revista de renome. Urey decidiu retirar seu nome do trabalho, por acreditar que Miller ganharia pouco crédito e visibilidade. Por isso, os livros didáticos costumam dar crédito somente a Miller, com exceção do Projeto Araribá, que aborda o tema com o enunciado "a teoria de Oparin-Haldane foi testada em laboratório, em 1953, pelos estadunidenses Staney Miller, estudante de Química, e Harold Urey, seu professor". O processo de publicação foi bem demorado, com trocas de editoras, editoras que não respondiam e outros problemas (BADA \& LAZCANO, 2012).

O impacto do artigo de Miller ultrapassou os muros da comunidade científica e adentrou o imaginário da população: as descargas elétricas e a formação da "sopa prebiótica" ganharam espaço em quadrinhos, livros, filmes, desenhos, entre outros meios midiáticos, mesmo que alguns estudos viessem a criticar o experimento (BADA \& LAZCANO, 2003). Associado a outros discursos, como o da Evolução, de Charles Darwin, o da estrutura do DNA, de Watson e Crick e o da teoria de Oparin-Haldane, Miller foi responsável na experimentação científica que a validou, de forma que "dado esse passo, os estudos de origem da vida tomaram maior fôlego empírico" (BARCELOS, 1999, p.12). Em outras palavras, esse Autor ganha o destaque pela elaboração de enunciados que ganharam aceitação no discurso científico, por esses se enquadrarem no método científico aceito na época, pois a hipótese precisa de um experimento que a comprove para ganhar status científico de verdade.

Os livros didáticos apresentam enunciados semelhantes, ao abordarem a teoria, o experimento e os três Autores. Informações geológicas de como seria a atmosfera primitiva da Terra 
são apresentadas anteriormente à apresentação de Oparin e Haldane, como pesquisadores que propuseram uma teoria para a Origem da Vida. A introdução das teorias é feita da seguinte forma:

Na década de 1920, o russo Aleksandr Ivanovich Oparin (1894-1980) e o inglês John B. S. Haldane (1892-1964) lançaram uma hipótese para explicar a origem na vida na Terra (Projeto Teláris).

Na década de 1920, dois pesquisadores propuseram, de forma independente, uma possível explicação para a origem de moléculas orgânicas e de sistemas orgânicos mais complexos antes do surgimento dos seres vivos. Esses pesquisadores foram o russo Aleksandr Oparin (1894-1980) e o inglês John Haldane (1892-1964) (Investigar e Conhecer).

A explicação sobre a origem da vida na Terra introduz uma das teorias mais conhecidas: a da evolução molecular. Suas bases foram formuladas pelos pesquisadores Aleksandr Oparin, russo, e John Haldane, inglês, na década de 1920 (Projeto Araribá).

O mesmo acontece nos livros que abordam o experimento de Miller:

Em 1953, o químico norte-americano Staney Miller (1920 - 2007) propôs um experimento para testar uma hipótese de formação de substâncias orgânicas (Companhia das Ciências). A teoria de Oparin-Haldane foi testada em laboratório, em 1953, pelos estadunidenses Staney Miller, estudante de Química, e Harold Urey, seu professor (Projeto Araribá). Em 1953, o cientista norte-americano Staney Miller (1930-2007) realizou um experimento no laboratório que tentou mostrar que os gases da atmosfera primitiva poderiam, em certas condições, formar algumas substâncias que ser encontravam nos seres vivos (Projeto Teláris).

A historicidade presente somente na data da formulação da teoria (Na década de 1920 e em 1953) e a descrição dos Autores apenas com suas nacionalidades (o russo, o inglês, o norteamericano/estadunidenses) são traços, ainda presentes, de uma historicidade de vertente positivista, na qual o contexto histórico, as influências teóricas, as divergências científicas, entre outros elementos, são silenciados.

Referente ao experimento de Miller, os livros tendem a trazer enunciados de que "hoje, acredita-se que a atmosfera primitiva não tinha exatamente os mesmos gases usados nesse experimento e que a origem da vida é um assunto que deve ser ainda muito discutido”, a exemplo do Projeto Teláris, e também:

Atualmente, acredita-se que a composição da atmosfera primitiva era diferente da que foi simulada nos experimentos de Miller e Urey e que talvez o fundo dos oceanos primitivos pudesse oferecer condições adequadas para a origem da vida. Mas isso não desmerece a importância histórica desse experimento e a teoria de Oparin-Haldane continua sendo uma possibilidade (Projeto Araribá Ciências).

Recentemente, alguns cientistas questionam o experimento de Miller devido à descoberta de que a composição da atmosfera primitiva era diferente da utilizada por Miller em seu experimento. Curiosamente, quando o experimento foi refeito utilizou-se essa outra composição da atmosfera, também se verificou a formação de substâncias orgânicas. E assim, mais uma vez, a Ciência caminha (Companhia das Ciências).

O experimento de Miller funcionou de acordo com o contexto histórico em que estava inserido, com os saberes produzidos em sua época, o que não retira dele a sua importância histórica, principalmente no que diz respeito ao seu papel na produção e na afirmação do discurso científico 
da teoria da evolução química gradual. Assim, a Ciência aparece como algo dinâmico que caminha, que deve ser ainda muito discutido e alguns de seus elementos continuam sendo uma possibilidade, aproximando-se de uma vertente epistemológica mais contemporânea.

A relação poder-verdade do discurso encontra-se presente nas minúcias de sua apresentação. Um dos exemplos mais evidentes está na abordagem da Teoria da Geração Espontânea, pelo livro didático Ciências, no qual o conteúdo está inserido na sessão Para Ler o Texto Científico, com a leitura de partes selecionadas de um artigo científico ${ }^{6}$ que, apesar de ser da história e filosofia da Biologia, não mostra o contexto histórico e/ou o jogo de interesses presentes na disputa experimental entre Pouchet e Pasteur, sendo a favor ou contra a Teoria da Geração Espontânea. Logo em seguida, é proposta uma atividade em grupo: "planejem um experimento cujos resultados sirvam como argumento contra a ideia da geração espontânea".

Portanto, a retirada do contexto histórico, social, político, econômico e ético da produção desses saberes, a não apresentação de qualquer outra teoria e o destaque dado aos experimentos em si faz com que o poder da verdade "a teoria da geração espontânea não está correta" seja exercido de forma a não deixar margem para questionamentos ou reflexão crítica sobre ela.

A ideia de que a vida poderia ter surgido de algo não vivo é uma possibilidade tanto na evolução química gradual, quanto na geração espontânea ou, como é associado na maioria das vezes, Abiogênese. Essa teoria é abordada de forma homogênea nos livros didáticos com enunciados como "de acordo com a teoria da geração espontânea ou abiogênese, algumas formas de vida poderiam simplesmente aparecer da matéria sem vida ou em decomposição”, presente no Projeto Araribá; e "acreditava-se que pequenos seres vivos, como moscas e girinos (larvas de sapo) podiam nascer a partir da matéria sem vida (bruta) [...] essa teoria é chamada geração espontânea ou abiogênese”, no Projeto Taláris. Esse ponto de interseção entre a evolução química gradual e a geração espontânea pode gerar uma confusão epistemológica, pois:

Algum acordo é feito nos processos de ensino e aprendizagem das Ciências biológicas, o falso da abiogênese ressurge verdadeiro, quando afirmamos (nós professores) que as células são o produto final de um emaranhado de reações químicas entre substâncias compostas por Carbono, Hidrogênio, Nitrogênio, Oxigênio etc. em um caldo primordial, contrariamente, a verdade da biogênese torna-se falsa, pois temos vida sem a necessidade de uma vida preexistente (VIEIRA, 2013, p. 60).

O que é comprovado, em enunciados da teoria da evolução química gradual, nos mesmos livros: "com base nesse resultado, os pesquisadores concluíram que seria possível produzir esses compostos orgânicos em condições abióticas, ou seja, sem ocorrência de vida”( Projeto Araribá);

${ }^{6}$ MARTINS, L. A. Pasteur e a geração espontânea: uma história equivocada. Filosofia e história da biologia, São Paulo, 2009, v.4, p 65-100. 
e "a formação do primeiro ser vivo a partir da matéria sem vida só teria sido possível em condições que não existem mais - e mesmo assim, esse processo teria levado muitos milhões de anos para ocorrer" (Projeto Taláris). Compreendemos que o embate possa estar na associação da palavra abiogênese especificamente à teoria da geração espontânea. Etimologicamente, esta palavra vem do grego, "a" como sufixo de negação, "bios" no sentido de vida e "genesis" como origem, ou seja, a uma origem sem vida. Apesar de ambas as teorias possuírem essa crença, a forma como aconteceu esse processo do surgimento por elementos sem vida é defendida de forma distinta.

Outro aspecto importante dessa teoria é que ela constitui o palco da maior disputa entre saberes relacionados com a Origem da Vida. Temos, no período da desvinculação gradativa do discurso científico com o filosófico, um movimento que procura sujeitar os saberes teológicos em detrimento de uma Ciência cada vez mais organizada e poderosa, possibilitando, assim, que a história natural emergisse no momento em que a filosofia mecanicista ${ }^{7}$ era bastante aceita e influente. Esse fato traz, para os naturalistas, desdobramentos metodológicos e epistemológicos, uma vez que:

Basicamente, a filosofia mecanicista requeria que o mundo natural fosse explicado somente em termos de movimento e rearranjos de partes da matéria. Mas, para além dessas concepções básicas, os filósofos mecanicistas estavam divididos. Suas teorias concernentes às causas do movimento e à mudança tinha uma imensa variedade de formulações, pois seria a matéria movida por um poder externo, um poder interno ou por nenhum poder? As três posições tiveram argumentos a favor e surgiram posições ideológicas que se prolongaram além do conteúdo filosófico (CASTAÑEDA, 1995).

As Ciências empíricas começam a ganhar ênfase, ditando um conhecimento de mundo, a partir da criação, fundamentada de forma dinâmica, de leis universais que explicariam os fenômenos naturais. É possível observar a presença desses dizeres em materiais didáticos contemporâneos, especificamente, na obra Companhia das Ciências, ao apresentar a imagem de como Francesco Redi realizou o experimento que "produziu evidencias de que os vermes que surgiam na carne eram, na verdade, larvas de moscas, que apareciam se as moscas pusessem ovos nela"

\footnotetext{
${ }^{7}$ Franz Borkenau em sua obra Der Uebergang vom feudalem zum bürgerlichen Weltbild (1933) concebe que "o sucesso dessa concepção traduz, na esfera da ideologia, o fato econômico constituído pela organização e difusão das manufaturas" de forma que o mecanicismo, teoria do animal-máquina de que o corpo biológico agiria como uma máquina funcionando de acordo com as leis universais da natureza, "dever-se-ia perceber as normas de economia capitalista nascente. Em outras palavras, a filosofia Mecanicista nasce e ganha forças no século XVII pela valorização da técnica e dos precedestes de uma sociedade capitalista”. Essa concepção recebeu críticas de que estaria anulando 150 anos de história ideológica e econômica, de modo que "foi a evolução do maquinismo a causa autêntica da concepção mecanicista do universo" (CANGUILHEM, 2012, p. 116-117).
} 


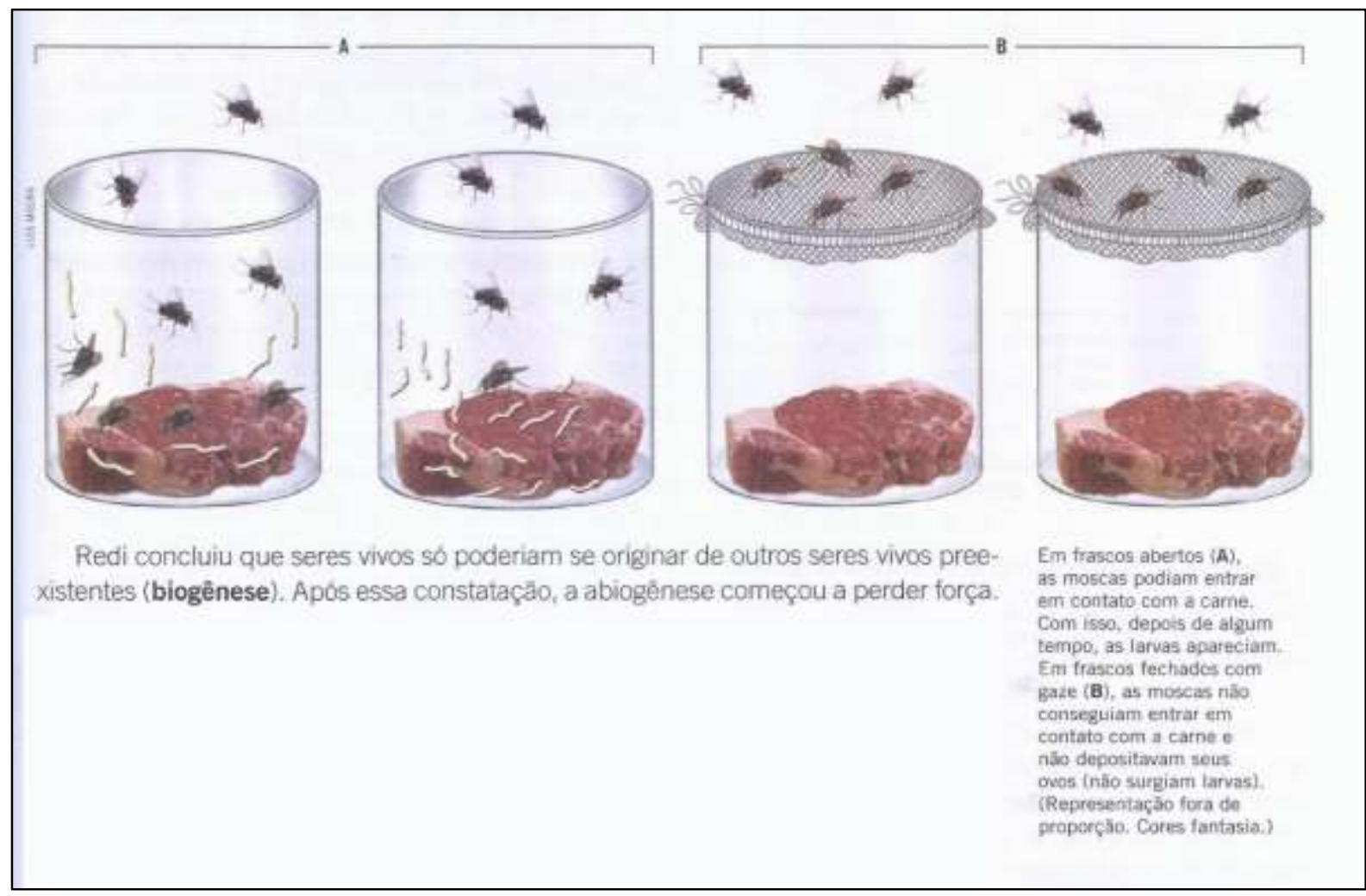

Figura 4 - Enunciado sobre o experimento de Redi Fonte: Companhia das Ciências (2015, p. 81).

Dessa forma, "Redi concluiu que seres vivos só poderiam se originar de outros seres vivos preexistentes (biogênese)", ou seja, partindo da observação experimental de um fenômeno específico, foi possível fundamentar a explicação universal de que "seres vivos só poderiam surgir de outros seres vivos". Um método próprio da história natural começa a surgir, apresentando que é a "reprodução que dá ao ser vivo um status distinto, onde a filosofia mecanicista, pela primeira vez, se apresenta inadequada, porém ela não é totalmente excluída no pensamento biológico nascente" (Castañeda, 1995).

O contexto permitiu o debate entre os estudiosos da época sobre geração, que abrangia as temáticas de reprodução, regeneração e origens dos seres vivos. Assim, as produções enunciativas e a circulação dos discursos de origem da vida estavam vinculadas às produções desses outros saberes. Duas grandes concepções epistemológicas de reprodução existiam: a epigênese e o préformismo (CARVALHO \& PRESTES, 2012).

A primeira sustentava-se na ideia de que os organismos eram formados, gradativamente, após a fecundação e as etapas que se seguiam ao processo reprodutivo. Os estudiosos que a apoiavam acreditavam na explicação da geração espontânea para a origem da vida. A segunda baseava-se na concepção de que o ser vivo já vinha estruturado nos "germes" reprodutivos, de forma 
que ao longo da vida só iam crescendo, sendo assim, os estudiosos que a apoiavam negavam a possibilidade da geração espontânea (CARVALHO \& PRESTES, 2012).

Essas duas teorias tinham como adeptos tanto filósofos quanto naturalistas, entretanto, os religiosos aceitavam a teoria pré-formista, pois ela abria possibilidade para a criação desses seres por meio de um Deus criador, afirmando, assim, o Criacionismo do discurso religioso, enquanto que os que afirmavam a epigênese eram ditos hereges por atribuir à natureza os poderes e as forças para a produção da vida (CARVALHO \& PRESTES, 2012).

A incorporação de novas técnicas e tecnologias para a produção desses saberes, como o microscópio e a lupa, possibilitou o surgimento de novos dizeres, principalmente pela inserção de elementos existentes em um mundo não visível pelo ser humano, como aparece no enunciado: "ainda no século XVII, o holandês Antonie van Leeuwenhoek (1632-1723) construiu um microscópio e observou um microrganismo pela primeira vez na história, abrindo novas possibilidades para os pesquisadores", do Companhia das Ciências, produzindo novos objetos, novos instrumentos conceituais e novos fundamentos teóricos que criariam explicações para legitimar as crenças ou de epigenesistas ou dos pré-formistas (MARTINS \& MARTINS, 1989). Além disso, alguns Autores foram importantes na circulação desses discursos.

Francesco Redi, muitas vezes vinculado à imagem de pioneiro nos experimentos que "derrubaram" a teoria da geração espontânea, na realidade, contribuiu na desqualificação do enunciado de que os vermes que surgiam em matéria putrificada eram frutos da geração espontânea. Entretanto, "mesmo acreditando que a putrefação não criava vida, Redi admite que a vida pode gerar uma vida diferente dela mesma. Por exemplo: intestinos e cérebros de animais produzindo vermes que os habitam" (MARTINS \& MARTINS, 1989, p. 8).

John Turberville Needham isolou caldo de carneiro quente em frascos fechados por cortiça, no intuito de averiguar se os animálculos que apareciam no caldo eram oriundos de algum elemento externo ou surgiam espontaneamente. Quando a presença dos animálculos foi verificada no caldo, após o isolamento, Needham interpretou que as suas crenças na geração espontâneas estavam corretas, fortalecendo a sua teoria da "força ativa da natureza". Importante ressaltar que, por ser um homem religioso, sempre teve o cuidado de colocar suas teorias no contexto do discurso religioso. Mesmo assim, teve que se defender de acusações de ateísmo (CARVALHO \& PRESTES, 2012). O único livro didático que fala desse Autor, o Projeto Araribá Ciências, expressa que:

Muitas vezes, o que as pessoas esperam que aconteçam em um experimento influencia a interpretação dos resultados. Needham, por exemplo, acreditava na geração espontânea. Você acha que isso pode ter influenciado a forma como ele interpretou os resultados dos 
experimentos que realizou? Se Needham não acreditasse na geração espontânea, teria usado a hipótese da "força vital” para explicar a origem da vida? (Projeto Araribá Ciências).

A interpretação dos resultados é feita a partir do discurso no qual o cientista está inserido. O enunciado presente nesse livro confronta o discurso de uma Ciência com resultados neutros e despretensiosos. Uma vez que, para Needham, a geração espontânea era uma verdade e seu experimento mostrou-se favorável ao que era esperado, não houve necessidade de questionar o método ou os resultados.

Essas conclusões foram apoiadas por Georges-Louis Leclerc de Buffon, já que elas harmonizavam com sua teoria das "moléculas orgânicas". Defensor da epigênese, Buffon formulou a hipótese de que as moléculas orgânicas que constituíam os seres vivos, no momento de sua morte, continuavam a existir, podendo constituir novos seres vivos mais simples. Logo, os animálculos encontrados por Needham seriam originados pelas moléculas orgânicas que ainda ficaram presentes na infusão do caldo de cordeiro (CARVALHO \& PRESTES, 2012).

Lazzaro Spallazani confrontou o experimento de Needham alegando que o caldo não tinha sido devidamente aquecido a ponto de matar todos os animálculos já existentes no caldo e que a cortiça não foi eficiente no isolamento do líquido com o meio externo. Assim, desenvolveu um experimento no qual diversos tipos de líquidos infusos eram colocados em frascos lacrados e fervidos, de forma que nenhum animálculo era observado no líquido posteriormente (CARVALHO \& PRESTES, 2012).

Louis Pasteur, motivado a ganhar o Prêmio Alhumbert ${ }^{8}$, dedicou-se à questão da geração espontânea. Católico convicto, defensor do Criacionismo, desde o início, vinha com ideias que se opunham à geração espontânea, o que provavelmente foi um fator fundamental para que ganhasse o prêmio. Isso porque:

A comissão nomeada para julgar os trabalhos tinha vários membros que eram declaradamente contrários à geração espontânea. Houve depois mudanças na comissão, e por fim todos os seus membros eram adversários dessa hipótese. Não se tratava, portanto, de um prêmio destinado ao melhor trabalho a favor ou contra a geração espontânea, e sim um prêmio para quem fizesse a melhor pesquisa contrária a essa ideia considerada tão perigosa (MARTINS, 2009, p. 74).

No seu experimento, Pasteur intencionava comprovar que, se a água contendo levedo de cerveja fosse fervida e não entrasse em contato direto com o meio externo, não surgiriam microrganismos no líquido. Dessa forma, a fervura ocorreu em frascos com gargalos em formato de

\footnotetext{
${ }^{8}$ Como a questão das gerações espontâneas trazia consequências não apenas científicas, mas também de âmbito filosófico, religioso e até mesmo político, em janeiro de 1860, a Academia de Ciências de Paris ofereceu um prêmio no valor de 2.500 francos (o Prêmio Alhumbert) para o melhor trabalho sobre o assunto (MARTINS, 2009, p. 74).
} 
"S". Os microrganismos só começaram a surgir após a introdução de algodão contendo poeira, levando à interpretação de que isso só ocorreu devido à existência desses microrganismos, ou ovos, ou esporos no pedaço de algodão. Contudo, não foi provado, por análise microscópica, a existência dos microrganismos na poeira do algodão (MARTINS, 2009).

É pertinente mencionar que o experimento de Pasteur não foi capaz de provar que a teoria da geração espontânea é errônea, diferentemente dos enunciados do Projeto Araribá: "Pasteur concluiu que os microrganismos estavam no ar e não surgiram espontaneamente no caldo de carne. Desde então, prevalece a teoria de que, nas atuais condições terrestres, um ser vivo só se origina de outro preexistente"; e do Companhia das Ciências: "com essas evidências, ele derrubou a ideia de que microrganismos tinham geração espontânea”. Na época, os intelectuais foram contra a escolha da Academia de premiar Pasteur, acreditando que outro participante, Félix Archimède Pouchet (1800 - 1876), um indivíduo conhecido e respeitado na época, apesar de ser defensor da geração espontânea, deveria ter ganhado (MARTINS, 2009, p.76).

Assim, é possível compreender que a apresentação desses experimentos é muito mais significativa no sentido de mostrar o desenvolvimento das técnicas, das experimentações e da análise de variáveis diferentes do que mostrar a negação da teoria da geração espontânea em si. Essa que, de acordo com a construção de tecnologia e a produção de outros saberes, de acordo com o seu período histórico, teve seus dizeres recriados e interpretados por discursos religiosos, filosóficos e científicos concomitantemente. Vale ressaltar que esse debate perdurou por séculos até que a produção tecnológica e de outros saberes possibilitassem a produção de novos discursos. E não pode ser atribuída a nenhum desses experimentos ou a nenhum desses Autores a refutação total da teoria da geração espontânea.

Outro aspecto importante que esse histórico dos Autores nos mostra é a presença dos conflitos, dos interesses e das relações de poder que estão presentes na produção do saber científico. Cientistas apoiando outros para legitimar seus enunciados, intelectuais, oscilando entre uma teoria ou outra, pelo grau de influência dos indivíduos que as defendem, pesquisadores que fazem Ciência motivados por prêmios e não pela curiosidade. Apenas um livro didático traz a relevância desses conflitos, o Projeto Araribá, por meio dos Autores Needham e Spallanzani: 


\section{Os experimentos de Needham e Spallanzani}

Mesmo após os experimentos de Redi, algumas pessoas acreditavam que a teoria da geraçăo espontânea ainda poderia ser aplicada para seres mais simples, como os microrganismos.

Em 1748, o pesquisador ingles John Needham realizou experimentos que o levaram a concluir que microrganismos surgiam espontaneamente no interior de recipientes de vidro contendo caldo nutritivo, mesmo depois de haver fervido o líquido (e supostamente matado os microrganismos que existiam Iá) e fechado os recipientes com rolha de cortiça, na tentativa de evitar a entrada de microrganismos do ar.

Em 1776, outro pesquisador, o italiano Lazzaro Spallanzani, contestou os resultados e repetiu os experimentos de Needham, fervendo o caldo por mais tempo e vedando os frascos hermeticamente. Dessa forma, nāo surgiram microrganismos no caldo. Spallanzani concluiu que o tempo de fervura e o sistema de vedaçăo utilizados por Needham nāo foram suficientes para evitar a contaminação do caldo por microrganismos.

Needham respondeu que a fervura prolongada feita por Spallanzani havia eliminado a "força vital", indispensável ao surgimento da vida. Spallanzani, entāo, quebrou alguns frascos, expondo seu conteúdo ao ar. Em pouco tempo, surgiram microrganismos. Needham argumentou novamente, sugerindo a hipótese de que a "força vital" havia retornado com a entrada de ar fresco. Spallanzani não conseguiu provar que Needham estava errado e a teoria da abiogênese para os microrganismos permaneceu.

Figura 5 - Enunciado sobre os conflitos entre Needham e Spallanzani Fonte: Projeto Araribá Ciências (2014, p. 27).

Diferentemente de enunciados como "nem todos aceitavam a ideia da geração espontânea. Em 1668, o médico italiano Francesco Redi (1626-1697) reparou que 'vermes' apareciam em lugares frequentados por moscas" e "mesmo depois de Redi provar que as larvas provinham de ovos de moscas adultas, muitas pessoas continuaram acreditando na ideia da geração espontânea em relação aos seres microscópicos”, do Projeto Teláris, que produzem uma concepção de cientista que pensa diferente e, por isso, precisa provar e convencer os demais da verdade científica que foi descoberta, enquadrando-se em uma vertente epistemológica mais positivista, na qual o cientista é um gênio que descobre o real funcionamento da natureza.

\section{CONSIDERAÇÕES}

A análise dos livros didáticos de Ciências do $7^{\circ}$ do Ensino Fundamental possibilita afirmar que a teoria da evolução química gradual ocupa lugar destacado, sendo esse o discurso aceito atualmente, tal como na comunidade científica. A geração espontânea aparece como elemento histórico-experimental, que foi comprovadamente refutado. Desta forma, é mais um conteúdo de caráter ilustrativo, que não apresenta um tratamento explicitamente dirigido à aprendizagem de conceitos

A associação do termo "abiogênese" direta e unicamente à teoria da geração espontânea constitui um obstáculo para a prática de ensino e para o processo de aprendizagem. Essas confusões ou desencontros epistemológicos precisam ser problematizados para que se alcance uma 
compreensão das características da teoria da evolução química gradual e da geração espontânea que esteja mais próxima do que é preconizado atualmente, em termos de ensino e História e Filosofia da Ciência, assim como a diferenciação das concepções que ambas trazem para explicar quais as condições e de que forma essa "Vida" surge na perspectiva conceitual.

Comportamentos vinculados aos cientistas, ênfase na experimentação, entre outros escritos, não são elementos despretensiosos. Esses compõem enunciados que estabelecem as possibilidades de circulação dos discursos sobre a produção e a legitimação do conhecimento científico, ainda que tais explicações permaneçam em produção nas comunidades científicas hegemônicas. Majoritariamente, a abordagem dos conflitos e dos interesses presentes no processo de produção desses saberes potencializados pelos estudos de HFC são minimizadas nas abordagens dos livros didáticos.

Grande parte dessas teorias são apresentadas com uma vertente historiográfica positivista, sem um contexto histórico consistente, retirando a percepção de que a circulação desses discursos ocorre há séculos e continua nos tempos atuais e de que a produção desses saberes se constitui em momentos de descontinuidade, não de forma acumulativa. Assim, é comumente difundida na forma de enunciados que retratam a aceitação ou a negação de determinada teoria de forma imediata, com resultados de experimentos incontestáveis, ignorando a importância da comunicação e da circulação de ideias na comunidade científica, que ocorrem de modo heterogêneo e na presença de inúmeros interesses, disputas e pesquisas. Essa apresentação ahistórica também dificulta a compreensão de que essas teorias e essas hipóteses, embora possam parecer incoerentes e rudimentares, eram perfeitamente lógicas e adequadas para o momento no qual foram produzidas, no que tange aos conhecimentos, às visões de mundo e às tecnologias da época.

Esses enunciados de Ciência como uma verdade absoluta, indiscutível, universal, com descobertas de cientistas geniais associados a uma vertente historiográfica positivista tendem a não possibilitar ao discente um espaço para reflexão e crítica do conteúdo abordado em sala de aula, indo de encontro aos objetivos da educação brasileira, preconizados na Base Nacional Comum Curricular e aos critérios estabelecidos no PNLD 2017.

Entretanto, alguns enunciados vinculados à epistemologia contemporânea já circulam nos livros didáticos. A funcionalidade de determinado experimento decorrente do momento histórico ao qual pertence; a incorporação de novas técnicas e tecnologias na produção do conhecimento, o que possibilita a emergência de novos saberes; o cientista que somente é capaz interpretar seu experimento em acordo com o discurso no qual está inserido trazem o discente para próximo de uma Ciência presente nos estudos contemporâneos da HFC. Assim, percebe-se a necessidade da 
aplicação mais efetiva da vertente historiográfica e epistemológica contemporânea nos livros didáticos.

A visualização dos discursos que circulam e de como eles se materializam no contexto escolar possibilita ao professor um exercício crítico, não só em relação ao conteúdo que é trabalhado, mas também em relação à abordagem que ele pretende desenvolver em suas aulas e à percepção de possíveis erros conceituais. Mas, para que isso ocorra de forma concreta, é imprescindível que a abordagem da HFC esteja presente na formação de professores, tornando-os capazes de realizar esse exercício crítico-reflexível de seus conteúdos. Assim, este trabalho constitui-se também um convite, em especial aos professores de Biologia, para embarcar em uma leitura da temática Origem da Vida e de outros temas científicos, na perspectiva da História e Filosofia da Ciência.

\section{AGRADECIMENTOS}

Agradecimentos à CAPES (Coordenação de Aperfeiçoamento de Pessoal de Nível Superior), pela concessão da bolsa de mestrado e pelo incentivo a esta pesquisa.

\section{REFERÊNCIAS}

ALVIM, M. H; ZANOTELLO, M. História das ciências e educação científica em uma perspectiva discursiva: contribuições para a formação cidadã e reflexiva. Revista Brasileira de História da Ciência, Rio de Janeiro, v. 7, n. 2, p. 349-359, 2014.

AZEVEDO, S. D. R. Formação discursiva e discurso em Michel Foucault. Filogênese Revista Eletônica, Marília, v. 6, n. 2, 2013.

BADA, J. L.; LAZCANO, A. Prebiotic soup--revisiting the miller experiment. Science, 300(5620), 745-746, 2003.

BADA, J. L.; LAZCANO, A. Stanley L. Miller. National Academy of Sciences, 2012.

BARCELOS, E. D. A sopa quente: breve histórico das teorias sobre a origem da vida e a vida extraterrestre (1920-1959). Revista Múltipla, Brasília, 4(6): 9 - 20, julho - 1999.

BARNES, D. From communication to curriculum. Penguin Books, 202p. 202. 1976.

BRASIL. Ministério da Educação. Base nacional comum curricular. Brasília, DF: MEC, 2018. Disponível em:<http://basenacionalcomum.mec.gov.br/wp-content/uploads/2018/02/bncc-20dezsite.pdf $>$. Acesso em: 20 jun. 2018.

BRASIL. Ministério da Educação. Secretaria de Educação Básica (SEB). Guia de Livros Didáticos PNLD 2017 - Ciências: ensino fundamental anos finais. Brasília, DF: SEB, 2016. 
CANGUILHEM, G. O Conhecimento da Vida. Rio de Janeiro: Forence, 2012.

CARVALHO, E. C.; PRESTES, M. E. B. Lazzaro Spallanzani e a geração espontânea: os experimentos e a controvérsia. Revista da Biologia, v. 9, n. 2, p. 1-6, 2012.

CASSIANO, C. C. F. O Mercado do Livro Didático no Brasil: da criação do Programa Nacional do Livro Didático (PNLD) à entrada do capital internacional espanhol (1985-2007). 2007. 252 f. Tese (Doutorado em Educação) - Programa de Pós-Graduação em Educação: História, Política, Sociedade, Pontifícia Universidade Católica de São Paulo, São Paulo, 2007.

CASTAÑEDA, L. A. História natural e as ideias de geração e herança no século XVIII: Buffon e Bonnet. História, Ciências, Saúde-Manguinhos, v. 2, n. 2, p. 33-50, 1995.

FOUCAUlT, M. A ordem do discurso. Aula inaugural no Collège de France, pronunciada em 2 de dezembro de 1970/Michel Foucault; tradução de Graciano Barbachan. 2 ed. São Paulo: Edições Loyola, 2004.

FOUCAULT, M. Arqueologia do saber. Tradução de Luiz Felipe Baeta Neves, -7ed. - Rio de Janeiro: Forense Universitária, 2008.

FOUCAULT, M. Ditos e Escritos: Estética - literatura e pintura, música e cinema (vol. III). Rio de Janeiro: Forense Universitária, p. 264-298. 2009.

FRISON, M. D.; VIANNA, J.; CHAVES, J. M.; BERNARDI F. N. Livro didático como instrumento de apoio para construção de propostas de ensino de ciênciasc naturais. Encontro Nacional de pesquisa em Educação em Ciências, Florianópolis, p. 1-13, 2009.

GRIMES, C.; SCHROEDER, E. A origem da vida, sob a ótica de licenciandos de um curso de Ciências Biológicas. Revista Electrónica de Enseñanza de las Ciencias. V. 12, n. 1, 2013, p. 126143.

HIDALGO, M. R., JUNIOR, Á. L. Reflexões sobre a inserção da História e Filosofia da Ciência no Ensino de Ciências. História da Ciência e Ensino: construindo interfaces, 14, 19-38. 2016.

KLEIN, O. J. A gênese do conceito de dispositivo e sua utilização nos estudos midiáticos. Estudos em comunicação, 1, 215-231. 2007.

MACHADO, J. R. C. EDUCAÇÃO, CIÊNCIA E REDENÇÃO ECONÔMICA EM UMA CAPITAL AS PERIFERIA DA MODERNIDADE: A Escola de Chimica Industrial na Belém dos anos 1920. 2016. 181 f. Tese (Doutorado em Educação em Ciências) - do Instituto de Educação Matemática e Científica, Universidade Federal do Pará, Pará. 2016.

MARTINS, L. A. C. P. Pasteur e a geração espontânea: uma história equivocada. Filosofia e História da Biologia, 4(1), 65-100, 2009.

MARTINS, L. A. C. P.; MARTINS, R. de A. Geração espontânea: dois pontos de vista. Perspicillum, v. 3, n. 1, p. 5-32, 1989. 
MILLER, S. L. A production of organic compounds under possible primitive earth conditions (Doctoral dissertation, University of Chicago). 1955.

MINAYO, M. C. DE S. (Org). Pesquisa social: teoria, método e criatividade. 33. ed. Petrópolis, RJ: Vozes. 2013.

NEGRETTI, C. As relações entre a concepção de natureza de F. Engels e a hipótese A. I. Oparin sobre o problema da origem da vida na terra. 2006. 114 f. Dissertação (Mestrado em História da Ciência) - Pontifícia Universidade Católica de São Paulo, São Paulo, 2006.

OUVERNEY, R da R.; LAGE, D. de A. A origem da vida na educação básica: uma abordagem a partir do método científico. Revista Práticas em Educação Básica, 1. 2016.

SOUZA, S. S. O livro didático e as influências ideológicas das imagens: por uma educação que contemple a diversidade social e cultural. Dissertação apresentada ao Programa de PósGraduação em Educação da Universidade Estadual de Feira de Santana. 2014.

VEIGA-NETO, A. Foucault \& a Educação. Belo Horizonte: Autêntica, 2003.

VIEIRA, E. P. de P. Ser vivo, ser espécie, ser classificado: epistemes, dispositivos e subjetivações no ensino de Ciências e Biologia. 2013. 126 f. Tese (Doutorado) - Universidade Federal do Pará, Instituto de Educação Matemática e Científica, Belém, 2013. Programa de PósGraduação em Educação em Ciências e Matemáticas.

ZAIA, D.A.M. Da Geração Espontânea à Química Prebiótica. Química Nova 26(2), 260-264, 2003.

Submetido em: 05 de setembro de 2020 .

Aprovado em: 02 de novembro de 2020. 